\title{
CARACTERIZAÇÃO TECNOLÓGICA DE MISTURAS SOLO-GRITS PARA PAVIMENTOS DE ESTRADAS FLORESTAIS: INFLUÊNCIA DO TRATAMENTO TÉRMICO DO GRITS NA RESISTÊNCIA MECÂNICA DAS MISTURAS ${ }^{1}$
}

\author{
Carlos Cardoso Machado², Reginaldo Sérgio Pereira ${ }^{3}$, Dario Cardoso de $\mathrm{Lima}^{4}$, Carlos Alexandre Braz de \\ Carvalho ${ }^{4}$ e Danuse Machado Pires ${ }^{5}$
}

\begin{abstract}
RESUMO - Analisou-se a influência do tratamento térmico do resíduo grits na resistência mecânica de misturas solo-grits para aplicações em pavimentos de estradas florestais. O programa de ensaios de laboratório englobou: (i) dois solos residuais de gnaisse da Zona da Mata Norte de Minas Gerais; (ii) um resíduo da indústria da celulose denominado grits, que é composto de cal não-hidratada e areia, entre outros produtos; (iii) amostras de grits submetidas ao tratamento térmico em mufla sob temperaturas de $600,700,800$ e $900{ }^{\circ} \mathrm{C}$ antes da moldagem dos corpos-de-prova das misturas solo-grits; (iv) corpos-de-prova das misturas preparadas com o grits tratado termicamente, com $24 \%$ de grits em relação ao peso seco dos solos, compactados nas energias dos ensaios Proctor intermediário e modificado e curados por 7 e 28 dias em câmara úmida, sob condições de aproximadamente $22{ }^{\circ} \mathrm{C}$ de temperatura e $100 \%$ de umidade relativa do ar; e (v) imersão completa dos corpos-de-prova das misturas solo-grits em água, pelo período de quatro horas, antes da determinação de suas resistências em ensaios de compressão não-confinada. Os resultados do programa de ensaios de laboratório indicaram que o tratamento térmico produziu amostras de grits mais reativas, podendo-se associar melhor desempenho mecânico às temperaturas de 800 e $900{ }^{\circ} \mathrm{C}$ para o solo 1 e $800{ }^{\circ} \mathrm{C}$ para o solo 2 .
\end{abstract}

Palavras-chave: Estabilização de solos, resíduo grits e tratamento térmico.

\section{TECHNOLOGICAL CHARACTERIZATION OF SOIL-GRITS MIXTURES FOR FOREST ROAD PAVEMENTS: INFLUENCE OF GRITS THERMAL TREATMENT ON THE MECHANICAL STRENGTH OF MIXTURES}

\begin{abstract}
The objective of this paper was to analyze the influence of grits thermal treatment on the mechanical strength of soil-grits mixtures. The laboratory testing program included: (i) two residual gneiss soils from the Zona da Mata, Northern Minas Gerais; (ii) waste from the cellulose industry, namely grits, composed by non-hydrated lime and sand, among others by-products; (iii) grits samples submitted to thermal treatment in a muffle at the temperatures of 600, 700, 800 and $900{ }^{\circ} \mathrm{C}$ before soils-grits specimens preparation; (iv) soils-grits specimens containing $24 \%$ of treated grits in relation to soil dry unit compacted at the intermediate and modified Proctor compaction test, and cured during 7 and 28 days in a moist room at the temperature of $22{ }^{\circ} \mathrm{C}$ and relative humidity close to $100 \%$; and (iv) complete immersion of cured specimens in water (4 hours) before testing for compressive strength using the unconfined compression test. Data from the laboratory testing program support that: ( $i$ ) thermal treatment produced more reactive grits samples; and (ii) best soilsgrits mechanical responses were associated to grits treatment temperatures of 800 and $900{ }^{\circ} \mathrm{C}$ for soil 1, and to $800{ }^{\circ} \mathrm{C}$ for soil 2 .
\end{abstract}

Keywords: Soils stabilization, grits waste and thermal treatment.

\footnotetext{
${ }^{1}$ Recebido em 07.07.2006 e aceito para publicação em 12.03.2007.

${ }^{2}$ Departamento de Engenharia Florestal da Universidade Federal de Viçosa. E-mail: <machado@ufv.br>.

${ }^{3}$ Departamento de Engenharia Florestal da Universidade de Brasília. E-mail: <reginaldosp@unb.br>.

${ }^{4}$ Departamento de Engenharia Civil da Universidade Federal de Viçosa. E-mail:<declima@ufv.br>; <cabraz@ufv.br>.

${ }^{5}$ Bolsista de Iniciação Científica da FAPEMIG.
} 


\section{INTRODUÇÃO}

Toneladas de resíduos são geradas pela indústria de celulose e papel, sendo cada um desses possuidores de composição química das mais variadas possíveis (CPRH, 1998). A finalidade final de tais resíduos, quando não são reaproveitados no processo industrial, são os aterros industriais. Consoli (2003) chamou a atenção para a disposição de resíduos em aterros, descrevendo que, além do limitado espaço para a disposição, incorrem os riscos ambientais passíveis de ocorrência, como contaminações do solo e do lençol freático.

Matos et al. (1996) mencionaram que, devido às necessidades de se encontrarem alternativas para a disposição dos resíduos gerados no processo industrial de celulose, estudos de técnicas de manejo, bem como a sua aplicação, devem ser executados de forma a permitir a incorporação segura ao solo, com o mínimo impacto sobre o meio ambiente. Segundo Albuquerque et al. (2002), certos resíduos estão sendo utilizados por produtores rurais com o objetivo de correção da acidez do solo, pelo fato de apresentarem hidróxido em suas composições. Os referidos autores ressaltaram, também, que nenhum critério é adotado para quantificar a dose a ser aplicada, o que pode comprometer as propriedades físicas e químicas do solo. Estudos nesse sentido foram desenvolvidos por Bellote et al. (1998), que apontaram para uma geração de $48 \mathrm{Mg}$ de resíduos para cada $100 \mathrm{Mg}$ de celulose produzida, destacando a inviabilidade da opção de disposição em aterro devido aos altos custos para implantação e manutenção e aos cuidados especiais no manuseio.

Resultados de estudos sobre a aplicabilidade do resíduo grits da indústria de celulose na estabilização de solos, com vistas à melhoria de subleitos de estradas florestais, foram apresentados por Pereira et al. (2006). Em prosseguimento a esses estudos, neste artigo, objetivou-se analisar a influência do tratamento térmico do resíduo grits na resistência mecânica de misturas solo-grits após a compactação, cura e imersão em água, para aplicações em pavimentos de estradas florestais.

\section{MATERIAL E MÉTODOS}

\subsection{Material}

Duas amostras de solo foram utilizadas neste estudo, representando solos residuais característicos da microrregião de Viçosa, MG, sendo designados por solo 1 e solo 2. De acordo com Ferraz (1996), a amostra 1, de avançada evolução pedológica, é classificada como Latossolo variação Una, profundo, bem drenado, proveniente do intemperismo de gnaisse, de ocorrência nas encostas mais suavizadas e com predominância da composição mineralógica presente nos argilominerais 1:1 e sesquióxidos de ferro e alumínio. O solo 2 é arenoso, de origem saprolítica, quartzoso, com horizonte C profundo e coloração acinzentada (FERRAZ, 1996). A Tabela 1 traz as características físicas dessas amostras, bem como as respectivas classificações rodoviárias pelo sistema americano Transportation Research Board (TRB). Ressalta-se que, segundo as especificações técnicas do Departamento Nacional de Infra-estrutura e Transportes (DNIT), constantes em seu manual de 1996, os solos 1 e 2, em suas formas naturais, não apresentam os valores mínimos de capacidade de suporte CBR $(80 \%)$ para serem empregados como camada de base de pavimentos rodoviários, mesmo quando de compactação em energia modificada.

Empregou-se, também, uma amostra do resíduo sólido industrial grits, obtida do processo de recuperação da soda cáustica durante a extração de celulose de madeira de eucalipto, que foi fornecida pela empresa CENIBRA S.A., situada na microrregião de Ipatinga, $\mathrm{MG}$. $\mathrm{O}$ grits é constituído por areia, pedregulho, calcário $\left(\mathrm{CaCO}_{3}\right) \mathrm{e}$ outras impurezas que não reagiram no processo, podendo possuir, também, quantidades de $\mathrm{CaO}, \mathrm{Ca}(\mathrm{OH})_{2} \mathrm{e} \mathrm{Na}_{2} \mathrm{CO}_{3}$. Esse resíduo foi coletado no pátio da empresa, imediatamente, à sua geração, em virtude da possível alteração de sua constituição química decorrente da exposição às intempéries climáticas no aterro industrial onde é depositado. Na Tabela 2, encontram-se os principais componentes químicos desse resíduo; ressalta-se que $42 \%$ do cálcio presente no grits encontra-se na forma de óxido de cálcio e o restante na forma de carbonato de cálcio, segundo dados de Machado et al. (2003).

Tabela 1 - Índices físicos e classificação TRB dos solos de Viçosa, MG

Table 1 - Physical index and TRB classification for soils from Viçosa, MG

\begin{tabular}{|c|c|c|c|c|c|c|c|}
\hline \multirow[t]{2}{*}{ Solo } & \multicolumn{3}{|c|}{ Granulometria (\%) } & \multirow[t]{2}{*}{$\gamma_{\mathrm{s}} *\left(\mathrm{kN} / \mathrm{m}^{3}\right)$} & \multicolumn{2}{|c|}{ Limites de Atterberg (\%) } & \multirow[t]{2}{*}{ Classificação TRB } \\
\hline & Areia & Silte & Argila & & LL & IP & \\
\hline 1 & 23 & 7 & 70 & 27,63 & 73 & 33 & A-7-5 (20) \\
\hline 2 & 72 & 22 & 6 & 27,01 & 27 & 10 & A-2-4 (0) \\
\hline
\end{tabular}

*Peso específico dos sólidos.

R. Árvore, Viçosa-MG, v.31, n.3, p.487-494, 2007 
Tabela 2 - Principais componentes químicos do resíduo grits Table 2 - Main chemical compounds of the grits waste

\begin{tabular}{cccccccc}
\hline $\begin{array}{c}\text { Constituinte } \\
\text { Químico }\end{array}$ & $\mathrm{P}$ & $\mathrm{K}$ & $\mathrm{Na}$ & $\mathrm{Ca}$ & $\mathrm{Mg}$ & $\mathrm{S}$ & $\mathrm{Al}$ \\
\hline$(\%)$ & 0,26 & 0,12 & 0,70 & 53,50 & 0,60 & 0,18 & 0,09 \\
\hline
\end{tabular}

Fonte: Machado et al., 2003.

\subsection{Metodologia de laboratório}

\subsubsection{Teor de resíduo e tratamentos térmicos}

Nas misturas solo-grits, utilizou-se o teor de $24 \%$ de grits, calculado em relação à massa de solo seco. Esse teor está associado aos melhores resultados de resistência mecânica encontrados por Pereira et al. (2006), em que as misturas solo-grits apresentaram os maiores valores para o Índice de Suporte Califórnia (CBR), suplantando, no caso da mistura solo $2+24 \%$ grits, o valor recomendado pelo DNIT para material a ser empregado em camada de base de pavimentos rodoviários. Com relação aos tratamentos térmicos, o grits foi submetido às temperaturas de 600, 700, 800 e $900{ }^{\circ} \mathrm{C}$, definidas em função dos resultados de resistência mecânica encontrados por Machado et al. (2003) no emprego de grits, tratado termicamente, em mistura com um solo 1. A sequiência de tratamento térmico do grits foi: (i) espalharam-se $10 \mathrm{~kg}$ de grits em uma bandeja de aço inoxidável e colocou-se o conjunto em uma mufla, com controle interno de temperatura e tempo; e (ii) atingida automaticamente a temperatura requerida, o grits permanecia exposto a ela pelo tempo de $1 \mathrm{~h}$ e era retirado da mufla, após o seu esfriamento até a temperatura ambiente. As perdas de massa de grits em cada tratamento térmico encontram-se na Tabela 3.

Tabela 3 - Perda de massa, em \%, do resíduo grits tratado termicamente

Table 3-Mass detriment, in \%, of the thermally treated grits waste

\begin{tabular}{|c|c|c|c|c|}
\hline \multirow[t]{2}{*}{ Perda de Massa (\%) } & \multicolumn{4}{|c|}{ Tratamento Térmico $\left({ }^{\circ} \mathrm{C}\right)$} \\
\hline & 600 & 700 & 800 & 900 \\
\hline Água* & 9,09 & 9,09 & 9,09 & 9,09 \\
\hline Outras** & 1,15 & 2,69 & 4,33 & 10,03 \\
\hline Total & 10,24 & 11,78 & 13,42 & 19,12 \\
\hline
\end{tabular}

*O grits se encontrava com $10 \%$ de umidade. **Perdas por calcinação (redução do carbonato de cálcio, presente no grits, em óxido de cálcio, pela eliminação do $\mathrm{CO}_{2}$ ).

\subsubsection{Preparação das misturas solo-grits}

Adicionaram-se $24 \%$ de grits aos solos 1 e 2, procedeu-se à homogeneização manual e peneiramento (\#4,8 mm), e acrescentou-se água, seguida por nova homogeneização manual e peneiramento, em quantitativos referentes ao teor de umidade ótima $\left(\mathrm{W}_{\mathrm{o}}\right)$ determinado nos ensaios de compactação realizados por Pereira (2005), referentes às energias intermediária e modificada. Os parâmetros ótimos de compactação $\left(\mathrm{W}_{\mathrm{ot}}\right.$ e $\left.\gamma_{\mathrm{dmax}}\right)$ dos solos e das misturas solo $+24 \%$ grits, obtidos por Pereira (2005), encontram-se na Tabela 4. As misturas assim produzidas foram acondicionadas em sacolas plásticas, que foram hermeticamente fechadas e deixadas em repouso pelo período de $4 \mathrm{~h}$ antes da compactação, em se tratando das misturas solo 1-grits, e compactadas imediatamente após a mistura, no caso das misturas solo 2-grits. Esses tempos entre a mistura e a compactação estão associados aos maiores valores de resistência mecânica encontrados por Pereira et al. (2006) nas misturas solo-grits.

\subsubsection{Moldagem dos corpos-de-prova}

Preparadas as misturas solo-grits passou-se a etapa de compactação dos corpos-de-prova nos parâmetros ótimos $\left(\mathrm{W}_{\mathrm{ot}} \mathrm{e} \gamma_{\mathrm{dmax}}\right)$ apresentados na Tabela 4 , nas energias de compactação intermediária e modificada. Os corposde-prova foram compactados no molde cilíndrico do ensaio de compactação Proctor $(\phi=100 \mathrm{~mm}$ e h $=127,3$ $\mathrm{mm}$ ) por processo dinâmico, em camadas iguais, com um soquete de massa igual a 4,536 kg e altura de queda de 467,2 mm. Obedeceu-se à Norma do DNIT referente ao ME-202 de 1994, na qual se determina que, para compactação na energia intermediária, devem-se aplicar 21 golpes, com o referido soquete, em três camadas no cilindro de Proctor, e 27 golpes, em cinco camadas no cilindro Proctor, para se atingir a energia modificada. Os corpos-de-prova foram moldados em tréplica, para cada tratamento, sendo fixados os seguintes limites para sua aceitação, de acordo com a recomendação da Norma DNIT-ME 202/94: (i) $\mathrm{W}_{\text {ot }}= \pm 0,50 \%$; e (ii) $\gamma_{\text {dmax }}= \pm 0,30 \mathrm{kN} \cdot \mathrm{m}^{-3}$. Caso contrário, procedeu-se a moldagem de três novos corpos-de-prova.

\subsubsection{Cura e imersão em água dos corpos-de-prova}

Os corpos-de-prova moldados foram embalados em sacolas plásticas, que foram hermeticamente fechadas e identificadas, e submetidos a períodos de cura, em câmara climatizada com umidade relativa do ar superior

R. Árvore, Viçosa-MG, v.31, n.3, p.487-494, 2007 
a $95 \%$, pelos períodos de 7 e 28 dias. Antes da ruptura em prensa específica, os corpos-de-prova foram submetidos, ainda, a dois tratamentos: (i) imersão em água pelo período de $4 \mathrm{~h}$, segundo a recomendação da norma do DNIT (1994a); e (ii) rompimento sem a fase de imersão em água.

\subsubsection{Determinação da resistência mecânica}

Para a determinação da resistência mecânica dos corpos-de-prova, curados e submetidos às condições de saturação, fez-se uso do ensaio de compressão nãoconfinada, segundo a metodologia proposta pelo DNIT (1994a). A obtenção do valor de RCNC (resistência à compressão não-confinada) foi realizada pela média aritmética das tensões de ruptura dos três corpos-deprova rompidos em prensa de compressão simples, com velocidade de $1,25 \mathrm{~mm} . \mathrm{min}^{-1}$, sendo a aquisição de dados obtida através da leitura em extensômetros com precisão de $0,01 \mathrm{~mm}$, admitindo-se uma tolerância de $\pm 10 \%$ em torno da média. Caso contrário, três novos corpos-de-prova foram novamente confeccionados.

\section{RESULTADOS E DISCUSSÃO}

\subsection{Avaliação da resistência mecânica}

As resistências mecânicas das misturas solo-grits, envolvendo o grits tratado e não-tratado termicamente, podem ser analisadas pelos valores de RCNC apresentados na Tabela 5, que se referem às misturas compactadas na energia intermediária e curadas a sete dias. Em todas as misturas solo 1-grits (tratado termicamente), os valores de RCNC foram maiores do que o valor encontrado na mistura solo 1-grits (sem tratamento térmico). Somente a partir da mistura com grits tratado a $700{ }^{\circ} \mathrm{C}$ foram notados incrementos de resistência mecânica em relação ao solo 1, em sua forma natural, sendo o maior incremento na mistura com grits tratado a $800{ }^{\circ} \mathrm{C}(39 \%)$. Com relação à resistência mecânica das misturas solo 2-grits (tratado termicamente), com exceção da mistura com grits tratado a $900{ }^{\circ} \mathrm{C}$, em todas as demais se observaram valores de RCNC superiores ao da mistura envolvendo o grits em sua forma pura. Acredita-se que, na mistura solo 2-grits (tratado a $900{ }^{\circ} \mathrm{C}$ ), a exposição do resíduo a essa temperatura levou à queima de partículas do grits, ultrapassando a temperatura de ocorrência da reação de calcinação. A RCNC do solo $2(168 \mathrm{kPa})$, em sua forma natural, foi potencializada pela adição de grits (tratado termicamente), sendo o maior incremento atingido para a mistura solo 2-grits (tratado a $800{ }^{\circ} \mathrm{C}$ ), em que a RCNC foi de $828 \mathrm{kPa}$.

\subsection{Influência da energia de compactação}

Os valores de RCNC das misturas solo-grits (tratado e não-tratado termicamente), quando compactadas na energia modificada e curadas a sete dias, são apresentados na Tabela 6. Nas misturas solo 1-grits (tratado termicamente), o aumento do esforço de compactação levou a incrementos superiores a $100 \%$ nos valores de RCNC encontrados n essas misturas compactadas na energia intermediária. O máximo valor de RCNC foi obtido na mistura com grits tratado a $800{ }^{\circ} \mathrm{C}(1.630 \mathrm{kPa})$, em que ocorreu um ganho de $86 \%$ em relação ao valor encontrado no solo 1 ( $877 \mathrm{kPa})$, em sua forma natural, compactado na energia modificada.

As misturas solo 2-grits (tratado termicamente) tiveram o seguinte comportamento decorrente do aumento da energia de compactação: (i) incrementos nos valores de RCNC nas misturas contendo grits tratado a 600, 700 e $800^{\circ} \mathrm{C}$, que foram inversamente proporcionais à maior temperatura de exposição do resíduo; (ii) queda brusca na mistura com grits tratado a $900^{\circ} \mathrm{C}$; (iii) com exceção da mistura com grits a $900^{\circ} \mathrm{C}$, nos demais tratamentos térmicos foram observados valores de RCNC superiores ao encontrado na mistura contendo grits não-tratado; e (iv) em comparação com o valor de RCNC do solo 2 (292 $\mathrm{kPa}$ ), em sua forma natural, compactado na energia modificada, as misturas solo 2-grits (tratado termicamente a 600, $700 \mathrm{e}$ $800^{\circ} \mathrm{C}$ ) proporcionaramincrementos de até $200 \%$ nesse índice, caso da mistura com grits tratado a $800{ }^{\circ} \mathrm{C}$.

Tabela 4 - Parâmetros ótimos de compactação das misturas solo-grits Table 4-Optimum compaction parameters for soil-grits mixtures

\begin{tabular}{lcccc}
\hline Misturas & \multicolumn{3}{c}{ Energia de Compactação } \\
\cline { 2 - 5 } & \multicolumn{2}{c}{ Intermediária } & $\mathrm{W}_{\mathrm{ot}}(\%)$ & $\gamma_{\mathrm{dmax}}\left(\mathrm{kN} \cdot \mathrm{m}^{-3}\right)$ \\
\hline Solo 1 Natural & $\mathrm{W}_{\mathrm{ot}}(\%)$ & $\gamma_{\mathrm{dmax}}\left(\mathrm{kN} \cdot \mathrm{m}^{-3}\right)$ & 26,49 & 15,37 \\
Solo 1 + 24 \% grits & 28,87 & 14,58 & 22,75 & 16,16 \\
Solo 2 Natural & 25,85 & 15,20 & 9,90 & 19,01 \\
Solo 2 + 24 \% grits & 11,38 & 18,33 & 11,24 & 18,59 \\
\hline
\end{tabular}


Tabela 5 - RCNC média, em kPa, das misturas solo $+24 \%$ grits (tratado termicamente e não-tratado) compactadas na energia intermediária e curadas a sete dias

Table 5 - UCS average, in kPa, for soil $+24 \%$ grits (thermally treated and non-treated) compacted at intermediate effort and cured for 7 days

\begin{tabular}{cccc}
\hline Grits & \multicolumn{2}{c}{ Mistura Solo 1 - Grits } \\
RCNC & \multicolumn{2}{c}{$\begin{array}{c}\text { Mistura Solo 2 - Grits } \\
\text { RCNC }\end{array}$} & \multicolumn{2}{c}{ Valor em kPa } & Ganho** \\
\hline STT $^{*}$ & Valor em kPa & \% Ganho* & 64,47 \\
$600^{\circ} \mathrm{C}$ & 189,26 & - & 276,04 \\
$700^{\circ} \mathrm{C}$ & 369,57 & - & 389,60 \\
$800^{\circ} \mathrm{C}$ & 492,99 & 14,57 & 619,38 \\
$900^{\circ} \mathrm{C}$ & 596,92 & 38,72 & 828,14 \\
\hline
\end{tabular}

*Sem tratamento térmico. **Em relação ao solo em sua forma natural compactado na energia do ensaio Proctor intermediário.

Tabela 6 - RCNC média, em kPa, das misturas solo $+24 \%$ grits (tratado termicamente e não- tratado) compactadas na energia modificada e curadas a sete dias

Table 6-UCS average, in kPa, for soil + 24\% grits (thermally treated and non-treated) compacted at modified effort and cured for 7 days

\begin{tabular}{|c|c|c|c|c|c|c|}
\hline \multirow[t]{3}{*}{$\begin{array}{c}\text { Grits } \\
\text { (Tratamentos Térmicos) }\end{array}$} & \multicolumn{3}{|c|}{$\begin{array}{c}\text { Mistura Solo } 1 \text { - Grits } \\
\text { RCNC }\end{array}$} & \multicolumn{3}{|c|}{$\begin{array}{c}\text { Mistura Solo } 2 \text { - Grits } \\
\text { RCNC }\end{array}$} \\
\hline & \multirow[t]{2}{*}{ Valor em $\mathrm{kPa}$} & \multicolumn{2}{|c|}{$\%$ Ganho } & \multirow[t]{2}{*}{ Valor em $\mathrm{kPa}$} & \multicolumn{2}{|c|}{$\%$ Ganho } \\
\hline & & $\mathrm{SN}^{* *}$ & $\mathrm{EI} * * *$ & & $\mathrm{SN}^{* *}$ & $\mathrm{EI} * * *$ \\
\hline $\mathrm{STT}^{*}$ & 297,07 & - & 56,96 & 542,34 & 85,99 & 96,47 \\
\hline $600{ }^{\circ} \mathrm{C}$ & 1175,70 & 34,02 & 218,13 & 742,26 & 154,55 & 90,52 \\
\hline $700{ }^{\circ} \mathrm{C}$ & 1042,28 & 18,81 & 111,42 & 783,36 & 168,64 & 26,47 \\
\hline $800^{\circ} \mathrm{C}$ & 1633,35 & 86,19 & 173,62 & 902,55 & 209,52 & 8,99 \\
\hline $900^{\circ} \mathrm{C}$ & 1413,76 & 61,16 & 150,17 & 106,59 & - & - \\
\hline
\end{tabular}

*Sem tratamento térmico. **Em relação ao solo em sua forma natural, compactado na energia do ensaio Proctor Modificado. ***Em relação à energia do ensaio Proctor Intermediário.

\subsection{Influência do período de cura}

Os resultados dos ensaios de compressão nãoconfinada das misturas solo-grits (tratado e não-tratado termicamente) compactadas e curadas a 28 dias encontram-se na Figura 1. Nessa figura, em cada barra vertical são representadas as taxas, em porcentagem, de incremento (+) ou redução (-) dos valores de RCNC, em relação as essas mesmas misturas curadas a sete dias. Foram observadas nas misturas solo 1-grits (tratado termicamente a 600,700 e $800^{\circ} \mathrm{C}$ ) reduções nos valores de RCNC, devido ao aumento do período de cura de 7 para 28 dias, tanto para compactação na energia intermediária quanto modificada, conforme os dados ilustrados na Figura 1a; na mistura com grits tratado a $600{ }^{\circ} \mathrm{C}$, foi observada a redução mais significativa $(40 \%)$. Comportamento distinto apresentou a mistura solo 1-grits tratado a $900{ }^{\circ} \mathrm{C}$, ou seja, ocorreram incremento na resistência mecânica dessas misturas quando curadas a 28 dias; as taxas de incrementos foram, respectivamente, de 180 e $110 \%$, nas energias intermediária e modificada, sendo nesta última atingido o valor de RCNC de $3.000 \mathrm{kPa}$. O comportamento das misturas solo 2-grits (tratado termicamente) compactadas e curadas a 28 dias pode ser descrito, de acordo com os dados da Figura 1b, da seguinte forma: (i) observaram-se incrementos nos valores de RCNC, em comparação com as misturas curadas a sete dias, somente a partir da mistura com grits tratado a $700{ }^{\circ} \mathrm{C}$; (ii) maiores taxas de incremento foram obtidas na mistura solo 2 -grits tratado a $900{ }^{\circ} \mathrm{C}$, as quais, compactadas na energia intermediária, tiveram incrementos de resistência de $250 \%$ e, na modificada, de $590 \%$, em comparação com as mesmas misturas curadas a sete dias; e (iii) os maiores valores de RCNC foram notados nas misturas solo 2-grits tratado a $800{ }^{\circ} \mathrm{C}$, compactada tanto na energia intermediária $(1.330 \mathrm{kPa})$ quanto na modificada $(1.300 \mathrm{kPa})$.

\subsection{Resistência em condição de saturação}

Nas Figuras 2 e 3, encontram-se os resultados dos ensaios de compressão não-confinada nas misturas solo-grits (tratado termicamente e não-tratado)

R. Árvore, Viçosa-MG, v.31, n.3, p.487-494, 2007 
compactadas, curadas e submetidas à fase de imersão, em água, pelo período de $4 \mathrm{~h}$. Nessas figuras, acima das barras verticais se encontram as reduções, em porcentagem, dos valores de RCNC obtidos de corposde-prova rompidos sem a fase de imersão em água. As misturas solo 1-grits (tratado termicamente) tiveram os seguintes comportamentos, como pode ser observado pela Figura 2: (i) compactadas na energia intermediária, curadas a sete dias e imersas em água por $4 \mathrm{~h}$, a melhor resposta de resistência obtida foi na mistura com grits tratado a $700{ }^{\circ} \mathrm{C}(\mathrm{RCNC}=280 \mathrm{kPa})$, sendo as taxas de reduções nos valores de $\mathrm{RCNC}$, devido à imersão em água, das misturas com grits tratado a 600, 700, 800 e $900{ }^{\circ} \mathrm{C}$, de $24,36,55$ e $74 \%$, respectivamente; (ii) compactadas na energia intermediária, curadas a 28 dias e imersas em água por $4 \mathrm{~h}$, a melhor resposta de resistência obtida foi na mistura com grits tratado a $900{ }^{\circ} \mathrm{C}$ $(\mathrm{RCNC}=1.000 \mathrm{kPa})$, sendo as taxas de reduções nos valores de RCNC, devido à imersão em água das misturas

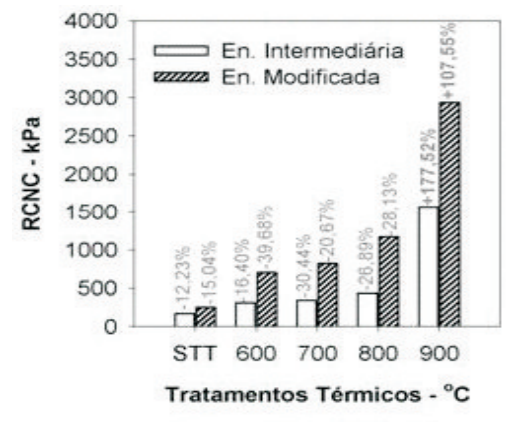

STT - Sem tratamento térmico com grits tratado a $600,700,800$ e $900{ }^{\circ} \mathrm{C}$, de 80,57 , 52 e $36 \%$, respectivamente; (iii) compactadas na energia modificada, curadas a sete dias e imersas em água por $4 \mathrm{~h}$, as melhores respostas de resistência obtidas foram nas misturas com grits tratado a 600 e $700{ }^{\circ} \mathrm{C}$ $(\mathrm{RCNC}=550 \mathrm{kPa})$, sendo as taxas de reduções nos valores de RCNC, devido à imersão em água das misturas com grits tratado a $600,700,800$ e $900{ }^{\circ} \mathrm{C}$, de 56, 50, 76 e $80 \%$, respectivamente. Ressalta-se, nesse tratamento, que nas misturas solo 1 + grits (sem tratamento térmico) ocorreram perdas totais de integridade dos corposde-prova quando imersos em água; e (iv) compactadas na energia modificada, curadas a 28 dias e imersas em água por $4 \mathrm{~h}$, a melhor resposta de resistência obtida foi na mistura com grits tratado a $900{ }^{\circ} \mathrm{C}$ $(\mathrm{RCNC}=2.300 \mathrm{kPa})$, sendo as taxas de reduções nos valores de RCNC devidas à imersão em água das misturas com grits tratado a $600,700,800$ e $900{ }^{\circ} \mathrm{C}$, de 54,58 , 64 e $23 \%$, respectivamente.

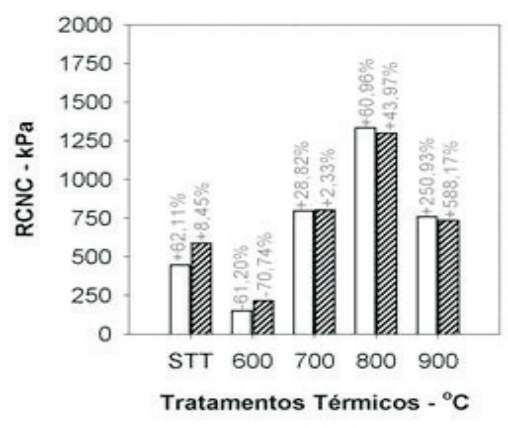

b) Mistura Solo $2+24 \%$ Grits

Figura 1 - RCNC média, em kPa, das misturas solo + 24\% grits (tratado termicamente e não- tratado) compactadas nas energias intermediária e modificada e curadas a 28 dias.

Figure 1 - UCS average, in $\mathrm{kPa}$, for soil $+24 \%$ grits (thermally treated and non-treated) compacted at intermediate and modified effort, and cured for 28 days.

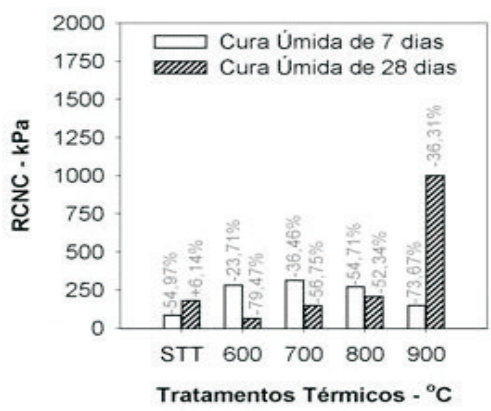

STT - Sem tratamento térmico a) Compactaçāo - En. Intermediária

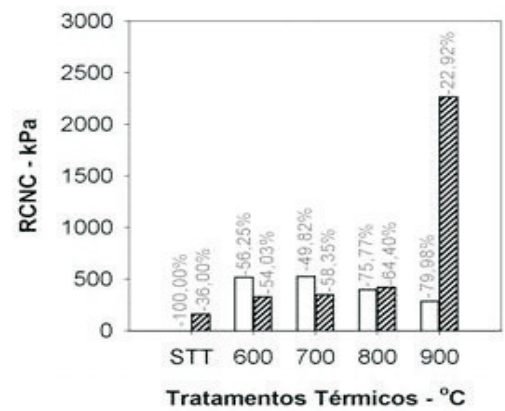

b) Compactaçăo - En. Modificada

Figura 2 - RCNC média, em kPa, das misturas solo $1+24 \%$ grits (tratado termicamente e não-tratado) compactadas, curadas e imersas por quatro horas em água.

Figure 2-UCS average, in $\mathrm{kPa}$, for soil $1++24 \%$ grits (thermally treated and non-treated) compacted, cured and submersion in water for 4 hours.

R. Árvore, Viçosa-MG, v.31, n.3, p.487-494, 2007 


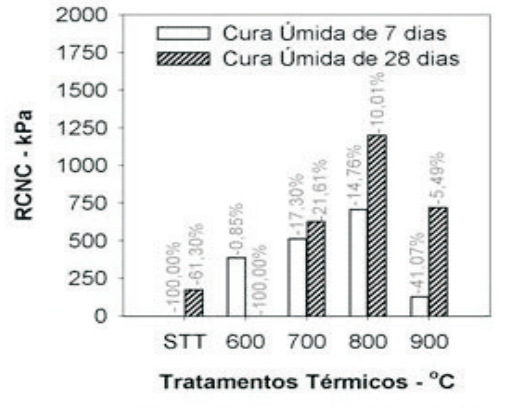

STT - Sem tratamento térmico a) Compactaçāo - En. Intermediária

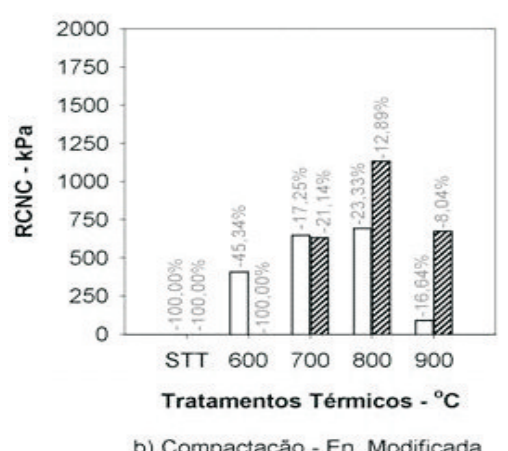

b) Compactaçăo - En. Modificada

Figura 3 - RCNC média, em kPa,das misturas solo $2+24 \%$ grits (tratado termicamente e não-tratado) compactadas, curadas e imersas por quatro horas em água.

Figure 3 - UCS average, in kPa, for soil $2+24 \%$ grits (thermally treated and non-treated) compacted, cured and submersion in water for 4 hours.

As misturas solo 2-grits (tratado termicamente) tiveram os seguintes comportamentos, como observados na Figura 3: (i) compactadas na energia intermediária, curadas a sete dias e imersas em água por $4 \mathrm{~h}$, a melhor resposta de resistência obtida foi na mistura com grits tratado a $800{ }^{\circ} \mathrm{C}(\mathrm{RCNC}=750 \mathrm{kPa})$, sendo as taxas de reduções nos valores de $\mathrm{RCNC}$, devido à imersão em água das misturas com grits tratado a 600, 700, 800 e $900{ }^{\circ} \mathrm{C}$, de $1,17,15$ e $41 \%$, respectivamente. Ressaltase que, na mistura solo 2-grits (sem tratamento térmico), os corpos-de-prova não suportaram a imersão; (ii) compactadas na energia intermediária, curadas a 28 dias e imersas em água por $4 \mathrm{~h}$, a melhor resposta de resistência obtida foi para a mistura com grits tratado a $800{ }^{\circ} \mathrm{C}$ ( $\mathrm{RCNC}=1.200 \mathrm{kPa})$, sendo as taxas de reduções nos valores de RCNC, devido à imersão em água das misturas com grits tratado a 600, 700, 800 e $900{ }^{\circ} \mathrm{C}$, de 100 (perda de integridade total), 22, 10 e 5\%, respectivamente; (iii) compactadas na energia modificada, curadas a sete dias e imersas em água por $4 \mathrm{~h}$, a melhor resposta de resistência obtida foi na mistura com grits tratado a $800{ }^{\circ} \mathrm{C}(\mathrm{RCNC}=750 \mathrm{kPa})$, sendo as taxas de reduções nos valores de RCNC devidas à imersão em água das misturas com grits tratado a 600, 700, 800 e $900{ }^{\circ} \mathrm{C}$, de $45,17,23$ e $17 \%$, respectivamente. Ressalta-se nesse tratamento que, nas misturas solo $1+$ grits (sem tratamento térmico), ocorreram perdas totais de integridade dos corpos-de-prova quando imersos em água; e (iv) compactadas na energia modificada, curadas a 28 dias e imersas em água por $4 \mathrm{~h}$, a melhor resposta de resistência obtida foi na mistura com grits tratado a $800{ }^{\circ} \mathrm{C}(\mathrm{RCNC}=1.150 \mathrm{kPa})$, sendo as taxas de reduções nos valores de RCNC devidas à imersão em água das misturas com grits tratado a 600, 700, 800 e $900{ }^{\circ} \mathrm{C}$, de 100 (perda total de integridade) 21, 13 e $8 \%$, respectivamente. Também, nesse tratamento, as misturas solo 1 + grits (sem tratamento térmico) não suportaram a imersão em água.

\section{CONCLUSÃO}

O tratamento térmico do resíduo grits tornou-o mais reativo para a estabilização dos solos, principalmente nas temperaturas de 800 e $900^{\circ} \mathrm{C}$, devido às reações de calcinação que ocorreram nesse intervalo, o que ficou evidenciado pelos resultados dos ensaios de compressão não-confinada realizados com as misturas solo $+24 \%$ grits (tratado termicamente). A resistência mecânica dessas misturas foi influenciada pela temperatura de exposição do grits, tipo de solo, energia de compactação, período de cura e pela imersão em água. Nas misturas solo 1-grits (tratado termicamente), as melhores respostas de resistência mecânica foram nos seguintes tratamentos: (i) grits tratado a $800{ }^{\circ} \mathrm{C}$, mistura compactada na energia modificada, período de cura de sete dias $(\mathrm{RCNC}=1.633 \mathrm{kPa})$; e (ii) grits tratado a $900{ }^{\circ} \mathrm{C}$, mistura compactada na energia modificada, período de cura de 28 dias $(\mathrm{RCNC}=3.000 \mathrm{kPa})$. De forma análoga, nas misturas solo 2-grits (tratado termicamente) as melhores respostas foram: (i) grits tratado a $800{ }^{\circ} \mathrm{C}$, mistura compactada na energia intermediária, período de cura de 28 dias $(\mathrm{RCNC}=1.330 \mathrm{kPa})$; e (ii) grits tratado a $800{ }^{\circ} \mathrm{C}$, mistura compactada na energia modificada, período de cura de 28 dias $(\mathrm{RCNC}=1.300 \mathrm{kPa})$.

R. Árvore, Viçosa-MG, v.31, n.3, p.487-494, 2007 


\section{AGRADECIMENTOS}

Ao CNPq e à FAPEMIG, pelo apoio financeiro a este projeto, bem como à CAPES e à UFV, respectivamente, pela concessão de bolsa de doutorado e pelas instalações físicas para a execução deste trabalho. Também, à empresa CENIBRA S.A., pelo fornecimento do resíduo grits.

\section{REFERÊNCIAS}

ALBUQUERQUE, J.A. et al. Propriedades físicas e químicas de solos incubados com resíduo alcalino da indústria de celulose. Revista Brasileira de Ciência do Solo, v.26, p.1065-1073, 2002.

BELlote, A. F. J. et al. Resíduos da indústria de celulose em plantios florestais. Boletim de

Pesquisa Florestal, n.37, 1998. p.99-106.

COMPANIA PERNAMBUCANA DE MEIO

AMBIENTE - CPRH. Roteiro complementar de licenciamento e fiscalização: indústria de papel e celulose. Recife: Publicações Projeto CPRH/GPZ, 1998. 95p.

CONSOLI, N. C. Processamento e utilização geotécnica de resíduos. In: SIMPÓSIO BRASILEIRODE GEOTECNIAAMBIENTAL-REGEO, 2003, Porto

Alegre Anais... Porto Alegre: 2003. p.497-510.

\section{DEPARTAMENTO NACIONALDE}

INFRAESTRUTURA DE TRANSPORTES - DNIT.

ME 201: Solo-cimento: compressão axial de corpos-de-prova cilíndricos: Método de ensaio. Rio de Janeiro: 1994a. 4p.
DEPARTAMENTO NACIONAL DE INFRAESTRUTURA DE TRANSPORTES DNIT. - ME 202: Solo-cimento: moldagem e cura de corpos-deprova cilíndricos: Método de ensaio. Rio de Janeiro: 1994b. 7p.

MACHADO, C. C.; PEREIRA, R. S.; PIRES, J. M. M. Influência do tratamento térmico do resíduo sólido industrial grits na resistência mecânica de um latossolo para pavimentos de estradas florestais. Revista Árvore, v.27, n.4, p.543-550, 2003.

MATOS, A. T.; COSTA, L. M. Lixiviação do resíduo do branqueamento da celulose em colunas de solo. Revista Árvore, v. 20, n.2, p.171- 177, 1996.

PEREIRA, R. S.; MACHADO, C. C.; LIMA, D. C. Compactação de misturas solo-grits para emprego em estradas florestais: influência do tempo decorrido entre mistura e compactação na resistência mecânica. Revista Árvore, v.30, n.3, p.421-427, 2006.

PEREIRA, R. S. Viabilidade técnica do emprego de resíduos da indústria de celulose para construção de estradas florestais. 2005. 330f. Tese (Doutorado em Ciências Florestais)-Universidade Federal de Viçosa, Viçosa, MG, 2005. 